Published in final edited form as:

Clin Cancer Res. 2009 April 15; 15(8): 2647-2656. doi:10.1158/1078-0432.CCR-08-2024.

\title{
Role of CCL11/eotaxin-1 signaling in ovarian cancer
}

\author{
Vera Levina $^{1,2}$, Brian M. Nolen ${ }^{1}$, Adele M. Marrangoni ${ }^{1}$, Peng Cheng ${ }^{1}$, Jeffrey R. Marks ${ }^{3}$, \\ Miroslaw J. Szczepanski ${ }^{1}$, Marta E. Szajnik ${ }^{1}$, Elieser Gorelik ${ }^{1,4,5}$, and Anna E. Lokshin $1,2,6, \#$ \\ 1 University of Pittsburgh Cancer Institute, Pittsburgh, PA 15213
}

2Department of Medicine, Pittsburgh, PA 15213

3Department of Surgery, Duke University Medical Center, Durham, NC 27710

4Department of Pathology, Pittsburgh, PA 15213

5Department of Immunology, Pittsburgh, PA 15213

6Department of Obstetrics, Gynecology and Reproductive Sciences, Pittsburgh, PA 15213

\begin{abstract}
Purpose-Tumor cell growth and migration can be directly regulated by chemokines. In the present study the association of CCL11 with ovarian cancer has been investigated.

Experimental design and results-Circulating levels of CCL11 in sera of patients with ovarian cancer were significantly lower than those in healthy women or women with breast, lung, liver, pancreatic or colon cancers. Cultured ovarian carcinoma cells absorbed soluble CCL11 indicating that absorption by tumor cells could be responsible for the observed reduction of serum level of CCL11 in ovarian cancer. Postoperative CCL11 levels in women with ovarian cancer negatively correlated with relapse-free survival. Ovarian tumors overexpressed three known cognate receptors of CCL11, CCR2, CCR3, and CCR5. Strong positive correlation was observed between expression of individual receptors and tumor grade. CCL11 potently stimulated proliferation and migration/ invasion of ovarian carcinoma cell lines, and these effects were inhibited by neutralizing antibodies against CCR2,3, and 5. The growth stimulatory effects of CCL11 were likely associated with activation of ERK1/2, MEK-1, and STAT3 phosphoproteins and with increased production of multiple cytokines, growth and angiogenic factors. Inhibition of CCL11 signaling by the combination of neutralizing antibodies against the ligand and its receptors significantly increased sensitivity to cisplatin in ovarian carcinoma cells. We conclude that CCL11 signaling plays an important role in proliferation and invasion of ovarian carcinoma cells and CCL11 pathway could be targeted for therapy in ovarian cancer. Furthermore, CCL11 could be used as a biomarker and a prognostic factor of relapse-free survival in ovarian cancer.
\end{abstract}

\footnotetext{
\#Address correspondence and reprint requests to Dr. Anna Lokshin, University of Pittsburgh Cancer Institute, Hillman Cancer Center, Rm. 1.18, 5117 Centre Ave., Pittsburgh, PA 15213. Phone: 412-623-7706, FAX: 412-623-1415, E-mail address: lokshina@ pitt.edu TRANSLATIONAL RELEVANCE

This is the first study to investigate the role of eotaxin-1 (CCL11) in ovarian cancer. The study has following translational implications. We demonstrate reduced levels of eotaxin-1 in sera of women with early stages ovarian cancer. Reduced eotaxin-1 levels could thus be utilized as a strong serum biomarker for early ovarian malignancy. Furthermore, postoperative CCL11 levels in women with ovarian cancer negatively correlated with relapse-free survival, suggesting that CCL11 could be prognostic factors of relapse-free survival in ovarian cancer. Strong positive correlation of expression of CCR2,3, and 5 with ovarian tumor grade indicate potential usefulness of expression of these receptors as prognostic biomarker of aggressive phenotypic behavior of ovarian tumor. We found that CCL11 provides a potent proliferative and migrating signaling via CCR2, CCR3, and CCR5, indicating that CCL11 is an important factor for growth and dissemination of ovarian tumor. Abrogating CCL11 signaling significantly sensitizes ovarian carcinoma cells to chemotherapy. These findings may allow targeting CCL11 pathway for ovarian cancer therapy.
} 


\section{Introduction}

In Western and Northern Europe, as well as in the United States, ovarian cancer represents the third most frequent cancer of the female genital tract. Worldwide, there are an estimated 191,000 women newly diagnosed each year (1-3). The majority of early-stage cancers are asymptomatic, and over three-quarters of the diagnoses are made at a time when the disease has already established regional or distant metastases. With presently available platinum-based chemotherapy, the 5-year survival for patients with clinically advanced ovarian cancer is only $15-20 \%$ although the cure rate for stage I disease is usually greater than $90 \%$ (1-3). Therefore, identification of factors and pathways responsible for the accelerated cancer growth is of critical importance and may lead to development of novel therapeutic targets.

It has been recently demonstrated that tumor cell growth can be directly regulated, among others, by chemokines, a group of proteins originally discovered as chemoattractants and activators of specific subsets of lymphocytes (4-6). Chemokines could induce distribution, trafficking and effector function of various cells. Recently, several publications reported regulation of growth and migration/invasion of several cancer types by signaling from chemokine/chemokine receptors autocrine loops (7-22). Stimulation of tumor growth and migration/invasion was reported for CXCL12 (SDF-1)/CXCR4 in ovarian (23) and breast (9) cancers; CCL21/CCR7 on thyroid tumor cell lines (13); CXCL13 (BCA-1)/CXCR5 in several mouse and human carcinoma cell lines including pancreatic and colon carcinoma cell lines (11); CCL20 (MIP-3 $\alpha$ )/CCR6 in colorectal cancer cells (7); in prostate cancer, MCP-1/CCR2 (10) and CCL5 (RANTES)/CCR5 (14); GRO $\alpha$ and GROß/CXCR2 in esophageal and lung cancers (15); IL-8/CXCR2) in epidermoid carcinoma cells (12). These results underscore potentially critical role of chemokines in tumor growth and invasion. Several retrospective studies in lung, colorectal, head and neck cancers and lymphoma indicate that expression of chemokine receptors in many cancers correlate with enhanced disease aggressiveness and poor prognosis (24-28). No experimental data exist on the similar effects of CCL11 (eotaxin-1) in tumor cells.

CCL11 (eotaxin-1) was originally discovered as an eosinophil-selective chemoattractant. CCL11 is a member of the CC chemokine family most homologous to the macrophage chemoattractant protein (MCP) subfamily (29). Genes encoding eotaxin and MCP chemokines are located on human chromosome 17q11, a region clustered with other $\mathrm{CC}$ chemokines (such as MIP-1, I-309, RANTES, and HCC-1,2) (30). CCL11 mRNA is expressed at high levels in the small intestine, colon, heart, kidney, and pancreas, and at lower levels in other tissues including the lung, liver, ovary, and placenta (31-33). Expression of CCL11 and CCR3 receptor was documented in human endometrium (34). CCL11 is an early gene product induced by proinflammatory cytokines in a variety of cell types in vitro. The airway epithelial cells express CCL11 mRNA in response to tumor necrosis factor (TNF)- $\alpha$, IL-1, or interferon (IFN)- $\alpha$ (31, 32). Furthermore, CCL11 is produced by fibroblasts, and IL-4 appears to be particularly important for CCL11 induction in cutaneous tissue (35). The CCL11 promoter in mice and humans has a nuclear factor NFkB-binding site, STAT-6-binding elements, IFN- $\alpha$ response elements, and a glucocorticoid response element. This may explain the observed up-regulation of CCL11 by TNF- $\alpha$, IL-4, IFN- $\alpha$, and glucocorticoids $(31,32)$. An important feature of chemokines is their ability to bind to the glycosaminoglycan (GAG) side chains of proteoglycans, predominately heparin and heparan sulfate, an interaction that protects CCL11 from proteolysis and potentiates chemotactic activity in vivo (36).

Specific activity of CCL11 playing a central role in eosinophil trafficking is mediated by the CC chemokine receptor-3 (CCR-3) (37,38). Recently, CCR2b and CCR5 receptors were reported to be partial agonists of CCL11 in monocytes $(39,40)$. Binding of CCL11 to these receptors induces a series of biochemical changes, including activation of Gi proteins, transient 
increases in intracellular calcium concentration, cytoskeletal rearrangements, activation of mitogen-activated protein MAP-kinase pathway, and rapid and prolonged receptor internalization into an endocytic compartment (41). These three receptors are shared among several chemokines; CCL11 shares, CCR3 with MCP-1, MCP-3, and RANTES (42), CCR2 with MCP-1, and CCR5 with RANTES and MIP-1 $\beta$ (43).

The association of CCL11 with cancer or potential CCL11 expression by tumor has not been adequately investigated. The only study exploring this association reported the overexpression of CCL11 receptor, CCR3, in renal cell carcinomas (RCC) and potent induction of proliferation of RCC cells by CCL11 (44). The presence of CCR3 in tumor samples correlated with the grade of malignancy indicating that CCL11 could promote progression and dissemination of CCR3-positive RCC (44). CCR2 expression by myeloma cells was reported to enhance migration of tumor cells via TNF $\alpha$-induced autocrine production of MCP-1 (13). Activation of CCR5 was shown to influence progression of breast cancer via regulation of p53 transcriptional activity (17) and CCR5 expression was also considered a prerequisite for the induction of MMPs in breast cancer cells, thus contributing to the invasive behavior of the cells (18). The above data indicate that CCL11 could be causally involved in tumorigenesis by facilitating tumor proliferation and metastasis. Several indirect lines of evidence also suggest that CCL11 can play a role in angiogenesis and metastasis. For example, it was shown that CCL11 is able to induce migration of human microvascular endothelial cells as well as the formation of blood vessels in vivo (45). The angiogenic response to CCL11 appeared to be direct and not mediated by eosinophil products (45). MicroArray analysis of human airway epithelial cell lines exposed to CCL11 demonstrated induction of several proangiogenic molecules including FGF-1,5,6, IL-6, VEGF A, and VEGF C (46). CCL11 was shown to induce MMP-2 mRNA, protein, and activity in smooth muscle cells. This effect was CCR3 receptormediated and dependent on activation of the EGFR (47).

In the present study we performed a comprehensive analysis of the possible involvement of CCL11 and its receptors CCLR2, CCLR3 and CCLR5 in ovarian cancer.

\section{Materials and Methods}

\section{Patients}

Serum from 342 healthy women were provided by Gynecologic Oncology Group (GOG) Blood Bank (Columbus, OH), Fox Chase Cancer Center Biorepository (Philadelphia, PA), and University of Pittsburgh Cancer Institute. Sera from patients with ovarian cancer, stages I-II $(n=215)$, and III-IV $(n=118)$ were from the GOG Blood Bank. Sera of age-matched women with endometrial cancer $(\mathrm{n}=231)$ were provided by the GOG and Dr. Karen Lu (MD Anderson Cancer Center, Houston, TX); with lung cancer $(n=67)$ were provided by UPCI, Pittsburgh, PA (Dr. Jill Siegfried); with breast cancer $(n=220)$ were from Duke Medical Center (Dr. Jeffrey Marks); with pancreatic $(n=285)$ and colorectal $(n=31)$ cancers were provided by Drs. Herbert Zeh and Randall Brand (UPCI). Sera were collected and stored as previously described (48). All sera were annotated with information regarding gynecologic diagnosis, ovarian cancer staging, cancer histology, grade, and age. In addition, sera from 21 women with serous ovarian adenocarcinoma were collected postoperatively at Duke University Medical Center and were provided by Dr. Jeffrey Marks. Sera were drawn at the first postoperative visit. Samples were annotated with dates of surgery and recurrence. All sera were from postmenopausal women. All serum collection protocols were approved by local institutional review boards.

\section{Cell lines}

Human ovarian cancer cell lines, OVCAR-3 and SKOV-3, were obtained from the American Type Culture Collection (ATCC, Rockville, MD, USA). Cells were grown in RPMI-1640 
culture media supplemented with 10\% FBS (Millipore Inc., Billerica, MA) with addition of $0.01 \mathrm{mg} / \mathrm{ml}$ insulin for OVCAR-3 as recommended by ATCC (49).

\section{Establishing of primary ovarian carcinoma cells from ascites}

Ascites was obtained at UPMC Magee Women's Hospital (Pittsburgh, PA) from 3 patients undergoing debulking surgery. The fluid was placed on ice and centrifuged to isolate the cellular component that was resuspended in RPMI-1640 media with 20\% FBS. Hypotonic lysis and sedimentation were used to remove erythrocytes. Cells were counted using a Coulter counter and were plated in $150 \mathrm{~cm}^{2}$ cell culture flasks at $5 \times 10^{6}$ cells/flask. Adherent cells were passaged 4 times prior to analysis.

\section{Reagents}

Hoechst 33342, doxorubicin, cisplatin and monensin were purchased from Sigma-Aldrich (Sigma-Aldrich, St. Louis, MO). Fluorochrome-conjugated antibodies against human CCR2 and CCR5 were from R\&D Systems, Inc. (Minneapolis, MN), antibody against CCR3 was from Abcam Inc. (Cambridge, MA). Antibodies against human CCRs (polyclonal goat antiCCR2, monoclonal rabbit anti-CCR3, and polyclonal rabbit anti-CCR5) for staining of formalin fixed tissues were from Abcam Inc. (Cambridge, MA). Mouse monoclonal antibody against eotaxin-1 (CCL11) that was used for both staining of formalin-fixed paraffin embedded (FFPE) tissue and neutralization of CCL11 activity was obtained from R\&D Systems, Inc. Secondary Abs conjugated with Alexa 488, were from Molecular Probes (Invitrogen, Carlsbad, CA). Mouse monoclonal neutralizing antibodies against CCR2,3,5 were from Genetex, Inc. (San Antonio TX). Recombinant human protein, CCL11, was purchased from Invitrogen/ Biosource (Camarillo, CA).

\section{Intracellular staining procedure}

Cells grown in 96-well plates were pretreated with monensin $(2 \mu \mathrm{M})$ for $24 \mathrm{~h}$ to inhibit secretion of CCL11 (50), fixed in 2\% PFA for $20 \mathrm{~min}$, washed in PBS, incubated with $0.1 \%$ Triton X-100 for $10 \mathrm{~min}$, and washed with PBS containing $1 \%$ of BSA (FACS buffer). Cells were then incubated with primary antibody against CCL11 for $1 \mathrm{~h}$ followed by incubation with secondary antibody conjugated with Alexa 488 for $1 \mathrm{~h}$. Cell nuclei were counterstained with $2 \mu \mathrm{g} / \mathrm{ml}$ Hoechst 33342 for $20 \mathrm{~min}$. All incubation and fixation procedures were performed at room temperature. Cell images were acquired using the Cellomics ArrayScan HCS Reader (20X objective) and analyzed using Target Activation BioApplication Software Module (ThermoFisher, Pittsburgh, PA).

\section{Immunohistochemistry (IHC)}

Formalin fixed paraffin embedded tissue microarray (TMA) of ovarian carcinoma (TMAOVC $1501 ; 150$ cores/75 cases) and normal ovarian epithelia (TMA-OV806; 60 cores/30 cases) (US Biomax Inc., Rockville, MD) were deparaffinized, rehydrated in xylene, ethanol, and $\mathrm{H}_{2} \mathrm{O}$. Antigen retrieval was performed using citrate buffer $\mathrm{pH} 6.0$ with 20 min steaming followed by cooling for 20 minutes. After unmasking, slides were blocked with $\mathrm{H}_{2} \mathrm{O}_{2}$. After pretreatment, EnVision+ System (Dako, Carpinteria, CA) was used for staining according to the manufacturer's instructions. In short, primary antibodies were diluted with Ab diluents (Dako) as follows: anti-CCR2 was diluted 1:200 anti-CCR3 was diluted 1:100, and anti-CCR5 was diluted 1:25. After overnight incubation with primary Abs, sections were first incubated with labeled horseradish peroxidase (HRP) anti-rabbit $\mathrm{Ab}$, or with biotynylated rabbit antigoat $\mathrm{Ab}(1: 5000)$ and then with HRP anti-rabbit $\mathrm{Ab}$, respectively. Next, slides were incubated with DAB-3,3'-diaminobenzidin. Sections were counterstained with Meyers hematoxylin and mounted in mounting medium. To eliminate non-specific binding of secondary Ab, tissue sections were incubated with a serum-free protein blocker prior to addition of primary Abs. 
Primary Abs were omitted in negative controls. Results were evaluated by two independent investigators (MJS and MES) and scored as positive or negative, when the percentage of stained tumor cells or normal epithelial cells in each section was $>25 \%$ or $<25 \%$, respectively. The level of staining intensity was recorded as none, weak, moderate or strong. For digital image analysis, the software Adobe Photoshop version 7.0 was used.

\section{RT-PCR analysis}

Total RNA isolated from normal ovarian epithelium and ovarian tumors was obtained from Applied Biosystems/Ambion (Austin, TX). Reverse transcriptase-polymerase chain reaction (RT-PCR) was performed for detection of CCL11 mRNA (40 cycles; eotaxin sense primer 5' - ACACCTTCAGCCTCCAACAT - 3'; antisense 5' - GGTCTTGAAGATCACAGCTT - 3'). The size of the eotaxin amplicon corresponded to its predicted size of $182 \mathrm{bp}$.

\section{Cellomics ArrayScan Automated Imaging}

The Cellomics ArrayScan HCS Reader (Cellomics/ThermoFisher, Pittsburgh, PA) was utilized to collect information on distribution of fluorescently labeled components in stained cells. The ArrayScan HCS system scans multiple fields in individual wells to acquire and analyze images of single cells according to defined algorithms. The scanner is equipped with emission and excitation filters (XF93, Omega Optical, Brattleboro, VT, USA) for selectively imaging fluorescent signals. Data were captured, extracted and analyzed with ArrayScan II Data Acquisition and Data Viewer version 3.0 (Cellomics), Quattro Pro version 10.0.0 (Corel, Ottawa, Ontario, Canada), and MS Excel 2002 (Microsoft, Redmond, WA).

\section{Proliferation assays}

Cancer cells were plated onto 96 -well plates at $2 \times 10^{3}$ cells per well. Next day human recombinant CCL11 was added to final concentration of $0.5-100 \mathrm{ng} / \mathrm{ml}$ and cells were grown for $72 \mathrm{~h}$. Cells were fixed, stained with Hoechst 33342, and were counted using the Cellomics ArrayScan HCS Reader (10x objective).

\section{Migration and invasion assay}

The chemotactic effects of CCL11 (2-10 ng/ml) on migration/invasion of tumor cells were measured in BD BioCoat Matrigel Invasion Chambers (BD Bioscences, San Jose, CA) according to manufacturer's protocol. The results were expressed as the number of cells migrating through Matrigel membrane in response to CCL11.

\section{Apoptosis assays}

Tumor cells grown in 6-well plates were pre-incubated with $5 \mathrm{ng} / \mathrm{ml}$ of CCL11 for $2 \mathrm{~h}$, then cisplatin $(2 \mu \mathrm{g} / \mathrm{ml})$ was added for the next $20 \mathrm{~h}$. Apoptosis was analyzed by flow cytometry using FITC-conjugated Annexin V and propidium iodide (PI) as previously described (51). Cell images were acquired using the Cellomics ArrayScan HCS Reader (20X objective) and analyzed using Target Activation BioApplication Software Module.

\section{Multiplex analysis of cytokine production by tumor cells}

Analysis of human cytokines and growth factors in cell culture medium was performed using multiplexing xMAP technology (Luminex Corp., Austin, TX). Multiplex kits for detection of 49 human cytokines were purchased from Bio-Rad Laboratories (Hercules, CA): MCP-3, GRO $\alpha$, CTACK, LIF, NGF, PDGF-BB, SCF, SCGF-B, SDF- $1 \alpha$, TRAIL, IFN- $\beta$; Invitrogen (Carlsbad, CA): IL-1a, IL-1 $\beta$, IL-2, IL-4, IL-5, IL-6, IL-7, IL-8, IL-10, IL-12p40, IL-13, IL-15, IL-17, GM-CSF, IFN- $\alpha$, TNF $\alpha$, MCP-1, MCP-2, IP-10, MIP-1 $\alpha$, MIP-1 $\beta$, RANTES, VEGF, bFGF, G-CSF, CCL11, HGF, MIG, sIL-2R, M-CSF, EGF, TNFRI, TNFRII, DR5, IL-1R $\alpha$, 
and sIL-6R; and Millipore (Billerica, MA): sICAM-1. Analyses of tumor supernatants were performed in 96-well microplate format according to appropriate manufacturer's protocols. Data were plotted against standard curves of serially diluted protein standards using a 4parametric curve fit and were expressed as pg per $1 \times 10^{6}$ tumor cells.

\section{Multiplex analysis of phosphoproteins}

Tumor cells were stimulated with $5 \mathrm{ng} / \mathrm{ml}$ of hrCCL11 for $0,5,15$, or $30 \mathrm{~min}$; cell lysates were prepared using Bio-Rad Bio-Plex Cell Lyses Kit, and analyzed using Bio-Rad 17-Plex Phosphoprotein kit for testing phosphoproteins, Akt, ATF-2, ERK1/2, GSK-3a/B, JNK, p38 MAPK, STAT3, STAT6, CREB, HSP27, IRS-1, MEK1, NFkB p65, p53, p70 S6 kinase, p90RSK and TrkA according to manufacturer's protocol.

\section{Multiplex analysis of transcription factors (TFs)}

Tumor cells growing in 6 well plates were incubated with $5 \mathrm{ng} / \mathrm{ml}$ of hrCCL11 for $0,5,15$, or 30. Nuclear extracts were prepared using the Procarta Transcription Factor Nuclear Extraction Kit (Panomics, Fremont, CA) according to manufacturer's instructions. Protein concentrations were measured using the Bio-Rad Protein Assay. Transcription factor analysis was performed using the Procarta Multiplex Transcription Factor Assay Kit designed for measuring the activities of NF-kB, AP1, AP2, CREB, HIF-1, STAT1, STAT3, STAT4, STAT5, Oct, GATA, ELK-1, FAST-1, p53, PAX-3, NF-1, NF-E2, NF-E1/YY1, ATF-2, ISRE, PAX-5, AR, ETS/ PEA, Nkx-2.5, E2F1, MyoD, PPAR, SMAD, RUNX/AML, BRN-3, CEBP, NF-Y, c-myb, ER, GR/PR, FKHR, HNF-1, MEF-2, NFAT and IRF transcription factors.

\section{Statistical analysis}

The Mann-Whitney test was used to determine statistical significance of differences in biomarker serum concentrations between patient groups. All in vitro experiments were repeated at least three times and mean \pm SD were determined. The significance of the effects of CCL11 was assessed using a two-tailed Student's t-test. For the comparison of multiple groups, a one- or two-way ANOVA test was applied. For all statistical analyses, the level of significance was set at a probability of $\mathrm{P}<0.05$.

\section{RESULTS}

\section{Analysis of CCL11 in sera of patients with ovarian cancer and healthy women}

Bead-based sandwich immunoassay was used to analyze CCL11 in sera of patients with ovarian cancer, healthy women, women with benign pelvic disease, and women with other cancers. Concentrations of CCL11 were significantly lower in sera of patients with ovarian cancer as compared with healthy women (Figure 1A). Patients with early stages of disease had significantly lower concentrations of CCL11 as compared with patients with late stages (Figure 1A). Serum CCL11 levels did not correlate with histology of ovarian cancer (data not shown).

CCL11 was measured in sera of age-matched women with endometrial, lung, breast, pancreatic, and colorectal cancers (Figure 1B). CCL11 concentrations were significantly lower in sera of patients with endometrial cancer as compared to control. Circulating CCL11 levels were significantly elevated in postmenopausal women with breast, lung, colorectal, and pancreatic cancers. Eotaxin levels in all these cancers were significantly higher than those in ovarian and endometrial cancers. Therefore, CCL11 likely plays a distinct role in gynecologic cancers. 


\section{Prognostic significance of CCL11 in ovarian cancer}

CCL11 was measured in sera of twenty one ovarian carcinoma patients after surgery and correlated with relapse-free survival (RFS). Serum levels in a subgroup of women with RFS of $<3$ years were compared with those in the group of RFS $>3$ years (Figure 1C). CCL11 concentrations were significantly $(\mathrm{p}<0.001)$ lower in the group with longer RFS.

\section{Absorption of CCL11 by ovarian cancer cells}

We hypothesized that decreased eotaxin serum concentrations are due to absorption of circulating ligand by cognate CCL11 receptors expressed on ovarian tumor. The absorption of human recombinant CCL11 by human carcinoma SKOV-3 cells was assessed. Concentration of CCL11 in cell culture media after incubation with SKOV-3 cells decreased by $32 \%$ indicating active absorption of this cytokine by cultured cells (Figure 1D). Decrease in CCL11 concentration in the in vitro experiment corresponded to that in patients where CCL11 is 30\% lower in ovarian cancer cases than in healthy controls.

\section{Expression of CCL11 and CCR2,3,5 by primary and established tumor cell lines}

OVCAR-3 and SKOV-3 ovarian carcinoma cells were stained using specific polyclonal goat anti-human CCL11 antibody. Both established (Figure 2A) and primary (Figure 2B) cell lines showed distinctive positive staining. Next, CCL11 mRNA expression was analyzed in ovarian tumors and normal ovarian epithelium (NOE) using RT-PCR (Figure 2C). CCL11 was equally expressed in both ovarian tumor and NOE. Surface expression of CCR2,3,5 receptors on established cell lines was analyzed by flow cytometry (Figure 2D) and in primary tumor by IHC (Figure 2E). SKOV-3 cells expressed predominantly CCR3 and to a smaller extent CCR2 receptor. CCR5 expression was very low. OVCAR-3 cells expressed all three receptors.

\section{Expression of CCR 2, 3 and 5 in tissue sections}

Expression of CCL11 receptors on tissue sections was analyzed by IHC on TMA of ovarian tumors ( 75 cases) and normal ovarian epithelia (30 control tissues). CCR2, CCR3 and CCR5 receptors were expressed in 17\%, 20\% and 30\% cases of healthy epithelia, respectively. The expression was weak relative to tumor tissue. In tumor tissues CCR2, CCR3 and CCR5 were expressed in $94 \%, 67 \%$ and $72 \%$ of tumors, respectively, and the intensity of staining ranged from weak to strong (Table 1). Expression of CCR2,3, and 5 was observed in serous, mucinous, and endometrioid histologies, with the highest expression in mucinous histology followed by serous, and by endometrioid (Table 1). The analyzed TMA did not contain clear cell carcinoma sections. Expression of all three receptors showed strong positive correlation with tumor grade (Table 1). No correlation with tumor stage could be observed (data not shown).

\section{Role of CCL11 in migration, proliferation, and apoptosis of ovarian carcinoma cells}

To ascertain potential functional role of CCL11 in ovarian cancer, its effects on cell proliferation and migration were evaluated. OVCAR-3 and SKOV-3 cells were incubated with $0-5 \mathrm{ng} / \mathrm{ml}$ of human recombinant CCL11 for $48 \mathrm{hrs}$, and cell migration/invasion was assessed as described in Methods. CCL11 induced migration/invasion of both ovarian carcinoma cell lines in a dose dependent manner (Figure 3A). Next we tested whether disruption of CCL11 signaling by neutralizing antibodies against CCL11 and its receptors, CCR2, CCR3, or CCR5, could affect cell migration. Neutralizing Abs against CCR2,3, and 5 significantly inhibited CCL11-induced migration/invasion in OVCAR-3 and SKOV-3 cell lines (Figure 3B). Combination of three antibodies had the most pronounced effect on migration/invasion in both cell lines (Figure 3B).

To measure proliferative effects of CCL11, cell numbers were counted using imaging cytometry. CCL11 potently stimulated growth in OVACR-3 and SKOV-3 cell lines in a dose- 
dependent manner (Figure 3C). Blocking individual CCL11 receptors significantly inhibited cell proliferation in OVCAR-3 cells (Figure 3D). Abrogation of CCL11 autocrine loop by neutralization of CCL11 itself and all three receptors almost completely abrogated proliferation in these cells (Figure 3D). In OVCAR-3 cells stimulated with CCL11, blocking CCR2,3, and 5 receptors significantly inhibited proliferation, and simultaneous neutralization of all three receptors had the most pronounced effect (Figure 3D). These results demonstrate the importance of CCL11 signaling for ovarian tumor cell proliferation Next we tested whether blocking CCL11 signaling could increase tumor cell sensitivity to cisplatin. Inhibition of CCL11 signaling by combination of anti-CCL11 and ant-CCR2,3,5 Abs did not induce apoptosis in untreated OVCAR-3 and SKOV-3 ovarian carcinoma cells data not shown). Blocking each individual receptor or neutralization of the ligand did not significantly increase the apoptotic effects of cisplatin. However, in combination these Abs significantly increased OVCAR-3 tumor cell sensitivity to the apoptotic effects of cisplatin in these cells (Figure 3E).

\section{CCL11 stimulates production of cytokines, growth and angiogenic factors, and adhesion molecules in ovarian carcinoma cell lines}

Eotaxin could elicit its proliferative effects either directly or via induction of cytokines or growth factors. We have analyzed concentrations of various cytokines and growth factors in cell culture media of ovarian OVCAR-3 and SKOV-3 cells after 24 hrs incubation with CCL11 $(2 \mathrm{ng} / \mathrm{ml})$. CCL11 potently upregulated secretion of chemokines, MIF, IL-8 (CXCL8); G-CSF, GM-CSF, M-CSF, cytokines/receptors: IL-6R and IL-8; growth/angiogenic factors: VEGF, and SDF-1 $\alpha$; and adhesion molecule, ICAM-1, in both cell lines (Figure 4). Some chemokines were differentially upregulated by CCL11 in these cells lines. In SKOV-3 cells CCL11 upregulated RANTES, MCP-1, GRO $\alpha$, MCP-1, IFN $\alpha 2$, IP-10, and TNF-R1, and DR5 receptors (Figure 4A), whereas in OVCAR cells MIP-1b, LIF, TNF $\alpha$, TNF $\beta$, PDGF-BB, SCF, bFGF, and LIF (Figure 4B) were elevated.

\section{Analysis of CCL11 signal transduction pathways in ovarian carcinoma cell lines}

The mechanisms and signaling pathways regulating the biological effects of CCL11 in tumor cells remain unknown. To analyze CCL11 signaling in ovarian carcinoma cell lines, OVCAR-3 and SKOV-3 cells were incubated with $5 \mathrm{ng} / \mathrm{ml}$ of hrCCL11 for 0, 5, and $15 \mathrm{~min}$, and phosphorylation of 17 proteins as listed in Methods was analyzed using multiplex bead-based assay. Of these 17 proteins, ERK1/2, MEK-1, and STAT3 were phosphorylated within 5 min in response to CCL11 receptors cross-linking (Figure 4C). Following phosphorylation, a rapid dephosphorylation occurred by 15 min of incubation.

Next, activation of 37 TFs (listed in Methods) following 5-30 min incubation with $5 \mathrm{ng} / \mathrm{ml}$ of CCL11 was analyzed using multiplex bead-based assay. NFkB, AP2, STAT4, ELK-1, FAST-1, p53, EST, E2F-1, RUNX, CEBP, c-myb, and IRF were activated more than 1.7-fold after 15 min incubation in CCL11 treated cells as compared with untreated cells (Figure 4D). Delayed activation suggests that CCL11 receptor cross-linking induced TF activation not directly but rather via transactivation of some growth factor receptors.

\section{DISCUSSION}

Until recently, eotaxin-1 or CCL11 was considered to be just an eosinophil-specific chemoattractant, and consequently was studied mostly in diseases characterized by an accumulation of eosinophils in tissues, notably allergic conditions, such as example, asthma, rhinitis and atopic dermatitis, and other inflammatory disorders, such as inflammatory bowel disease, eosinophilic gastroenteritis and pneumonia (52). Since CCL11 has been poorly investigated outside the realm of lymphoid cells, little is known about its biological significance in different cell types, normal or malignant. 
In this study, for the first time we demonstrate cancer-dependent changes in serum eotaxin levels in patients with ovarian cancer indicating possible important role of CCL11 in ovarian tumor growth and invasion. We hypothesized that this reduction could be due to sequestration of soluble CCL11 by cognate receptors expressed on ovarian cancer cells. In support of this hypothesis, we demonstrate overexpression of CCL11 receptors in cultured ovarian carcinoma cells. Our comparative analysis of CCL11 receptor expression in normal ovary and ovarian cancer revealed overexpression of all three CCL11 receptors (CCR2, CCR3 and CCR5). Furthermore, we showed that cultured ovarian carcinoma cells could absorb and deplete CCL11 exogenously added to cell culture medium. Of note, the extent of depletion corresponded to the extent of decrease of CCL11 levels in serum of ovarian cancer patients compared with healthy women. An alternative explanation of lower serum CCL11 levels in ovarian and endometrial cancers would be immunosuppression resulting in inhibition of CCL11 secretion by lymphoid cells. However, this explanation would contradict observed elevated CCL11 levels in late stage (III-IV) ovarian cancer and in non-gynecologic cancers that often associated with immunosuppression. Interestingly, eosinophils are rarely seen in ovarian tumor microenvironment (53). This could be due by the fact that most of produced CCL11 is rapidly bound to cognate receptors overexpressed by ovarian tumor and internalized making it unavailable for eosinophil recruitment.

We observed an important association of lower serum CCL11 with longer RFS. Although study population is small and presented data have to be validated in a larger set, these results indicate potential significance of CCL11 as a prognostic biomarker of ovarian cancer. It was shown that production of CCL11 is regulated by Th2 and Th1 related cytokines. IL-4, and TNF- $\alpha$ stimulate, whereas IFN- $\gamma$ inhibits CCL11 production in fibroblasts (54). It is possible that reduction of serum CCL11 in ovarian carcinoma patients is due to decrease of IL-4 and TNF$\alpha$ and/or increase IFN- $\gamma$. In fact, levels of IFN- $\gamma$ were significantly $(p<0.05)$ higher in the group with longer RFS (our unpublished observation).

We have reported expression of the three known CCL11 receptors, CCR2,3, and 5 in ovarian cancer both in vitro and in vivo. CCL11 receptors in ovarian carcinoma are functionally active as CCL11 treatment manifested in phosphorylation of ERK1/2, MEK-1, and STAT3 and activation of numerous transcription factors. Activation of ERK1/2 (MAPK-1) and MEK-1 by CCL11 in eosinophils has been reported by Kampen et. al (55). The ability of MAPK-1 to activate STAT3 and CREB was also demonstrated (56-58). CCR2 can rapidly activate MEK and ERK1/2 (59), and all three receptors can activate ERK1/2, and MEK via STAT3 (60). Therefore, the downstream CCL11 signaling in ovarian tumor cells and eosinophils is similar. Activation of a wide variety of transcription factors by CCL11 occurs relatively late, i.e. at least $15 \mathrm{~min}$, after receptor binding and therefore most likely results from transactivation of other growth factor receptors, and triggering the cascade of other cytokines and growth factors signaling.

Normal physiological functions of chemokines include stimulation of proliferation (61), extravasation (62-64), and migration (65) of leukocytes. Limited evidence also suggests that chemokine receptor activation leads to increased resistance to cyclohexamide-induced apoptosis in T cells, possibly via activation of Akt and its downstream effectors (66). These processes could reflect in the role of chemokines in tumor growth, progression, and metastasis (67). Our data indicate that CCL11 stimulates proliferation and migration/invasion of ovarian carcinoma cells. These effects could be mediated by multiple cytokines that are upregulated by CCL11. CCL11 may potentially facilitate ovarian tumor growth via upregulation of IL-8, VEGF, FGFb, PDGF-BB, and others; and tumor dissemination at several key steps, including adherence of tumor cells to endothelium via ICAM, extravasation from blood vessels via MMPs, angiogenesis via FGFb, IL-8, and VEGF. 
The biological effects of individual eotaxin receptors were not investigated in ovarian cancer cells. Strong proliferative and chemotactic effects of CCL11 in ovarian carcinoma cells were likely mediated by CCR2,3,5 receptors as neutralizing antibodies to these receptors abrogate CCL11 induced proliferation and migration/invasion. All three receptors are likely important for both processes since inhibition of all three receptors most potently abrogated CCL11 effects. Mediating of proliferative and metastatic activity of ovarian tumor by CCR2,3,5 receptors could explain the observed strong positive correlation of expression of these receptors with ovarian tumor grade. This observation also suggests that expression of these receptors may represent a useful prognostic biomarker of aggressive phenotypic behavior of ovarian tumor.

The affinity of CCL11 binding to CCR2 and CCR5 is lower than that to CCR3 as was demonstrated in monocytes $(39,40)$, although this may not reflect the real situation as Gprotein-coupled receptors could function as heterodimers (68). It must be noted that CCL11, similar to other chemokines, shares its three receptors with other members of chemokine family, e.g. CCR3 receptor is shared with MCP-1, $-2,-3,-4$, RANTES, and HCC-2; CCR-2 is also receptor for MCP-1, -2, -3, -4, HCC4, and eotaxin-2, -3, whereas CCR5 interacts with RANTES, MIP-1 $\alpha$, MIP-1b, HCC1 and HCC4 (69). Such redundancy indicates that lack of one chemokine can be compensated by other chemokines in cellular processes emphasizing critical importance of intact chemokine signaling for normal physiologic processes. Indeed, when individual chemokines or their receptors have been deleted in mice, defects have been relatively subtle (67).

Our findings that ovarian carcinoma cell lines produce CCL11 and overexpress all three of its receptors, CCR2, CCR3, and CCR5 indicate activation of autocrine loops of eotaxin signaling in ovarian cancer. Our experiments with neutralizing antibodies show that proliferation of ovarian carcinoma cells is seriously compromised in the absence of CCL11 signaling.

Furthermore, blocking of CCL11 signaling potentiates chemotherapy induced apoptosis in ovarian carcinoma cell lines. This important finding may open new opportunities for exploring CCL11 signaling for ovarian cancer therapy. Small molecule inhibitors of CCL11 receptors are available. Maraviroc, an allosteric inhibitor of CCR 5 is currently used for treatment of HIV-1 infection (70), and other diseases, such as rheumatoid arthritis (71) and respiratory disease (72) have been suggested as possible targets for this CCR5 antagonist. Development of UCB35625, a potent, selective small molecule inhibitor of CCR1 and CCR3A, was recently reported (73).

It must be noted that targeting CCL11 receptors for cancer therapy is not straightforward due to their pleiotropic effects. For example, CCR5 has been reported to control antitumor responses by participating in chemotaxis of memory and activated naïve T cells, and it is required for T cell activation (74). Similarly, transfer of MCP-3 gene that shares CCR2 and CCR3 receptors with CCL11 elicits tumor rejection by activating type I T cell-dependent immunity (75). Furthermore, it was demonstrated that CCR5 activated tumor suppressor p53 in breast cancer cell lines, and abrogation of CCR5 expression enhanced proliferation of tumor cells bearing wild-type 553 in a mouse breast cancer xenograft model (76). Therefore, further studies in animal models of ovarian cancer are necessary to evaluate complex systemic effects of abrogation of CCL11 signaling.

In summary, we demonstrate a strong association of CCL11 with ovarian cancer. Our experimental evidence indicates a potentially important role of CCL11 in ovarian cancer growth and metastasis. These results warrant further investigation of the role of CCL11 in the initiation and progression of ovarian cancer. Blocking the autocrine loop of CCL11 and its receptors could be targeted for ovarian cancer therapy. CCL11 and possibly CCR2, CCR3, and CCR5 could be prognostic factors of relapse-free survival in ovarian cancer. 


\section{ACKNOWLEDGEMENTS}

We are grateful to Gynecologic Oncology Group Blood Bank (Columbus, OH), Dr. Karen Lu (MD Anderson Cancer Center, Houston, TX), Dr. Jill Siegfried, Dr. Herbert Zeh, III, and Dr. Randall Brand (University of Pittsburgh) for providing serum samples. This work was supported by NIH grants: EDRN Associate Member Award, RO1 CA098642, R01 CA108990, P50 CA083639, and Avon (NIH/NCI), and UPCI Hillman Fellows Award (AEL) and DOD, IDEA Award BC051720, Harry J. Lloyd Charitable Trust and Hillman Foundation (EG).

\section{REFERENCES}

1. Baker TR, Piver MS. Etiology, biology, and epidemiology of ovarian cancer. Seminars in surgical oncology 1994;10(4):242-8. [PubMed: 8091065]

2. Boente MP, Schilder R, Ozols RF. Gynecological cancers. Cancer chemotherapy and biological response modifiers 1999;18:418-34. [PubMed: 10800496]

3. Holschneider $\mathrm{CH}$, Berek JS. Ovarian cancer: epidemiology, biology, and prognostic factors. Seminars in surgical oncology 2000;19(1):3-10. [PubMed: 10883018]

4. Murooka TT, Ward SE, Fish EN. Chemokines and cancer. Cancer treatment and research 2005;126:1544. [PubMed: 16209061]

5. Rollins BJ. Inflammatory chemokines in cancer growth and progression. Eur J Cancer 2006;42(6): 760-7. [PubMed: 16510278]

6. Zlotnik A. Chemokines and cancer. International journal of cancer 2006;119(9):2026-9.

7. Brand S, Olszak T, Beigel F, et al. Cell differentiation dependent expressed CCR6 mediates ERK-1/2, SAPK/JNK, and Akt signaling resulting in proliferation and migration of colorectal cancer cells. Journal of cellular biochemistry 2006;97(4):709-23. [PubMed: 16215992]

8. Jinquan T, Jacobi HH, Jing C, et al. CCR3 expression induced by IL-2 and IL-4 functioning as a death receptor for B cells. J Immunol 2003;171(4):1722-31. [PubMed: 12902471]

9. Kishimoto H, Wang Z, Bhat-Nakshatri P, Chang D, Clarke R, Nakshatri H. The p160 family coactivators regulate breast cancer cell proliferation and invasion through autocrine/paracrine activity of SDF-1alpha/CXCL12. Carcinogenesis 2005;26(10):1706-15. [PubMed: 15917309]

10. Lu Y, Cai Z, Galson DL, et al. Monocyte chemotactic protein-1 (MCP-1) acts as a paracrine and autocrine factor for prostate cancer growth and invasion. The Prostate 2006;66(12):1311-8. [PubMed: 16705739]

11. Meijer J, Zeelenberg IS, Sipos B, Roos E. The CXCR5 chemokine receptor is expressed by carcinoma cells and promotes growth of colon carcinoma in the liver. Cancer research 2006;66(19):9576-82. [PubMed: 17018614]

12. Metzner B, Hofmann C, Heinemann C, et al. Overexpression of CXC-chemokines and CXCchemokine receptor type II constitute an autocrine growth mechanism in the epidermoid carcinoma cells KB and A431. Oncology reports 1999;6(6):1405-10. [PubMed: 10523720]

13. Sancho M, Vieira JM, Casalou C, et al. Expression and function of the chemokine receptor CCR7 in thyroid carcinomas. The Journal of endocrinology 2006;191(1):229-38. [PubMed: 17065406]

14. Vaday GG, Peehl DM, Kadam PA, Lawrence DM. Expression of CCL5 (RANTES) and CCR5 in prostate cancer. The Prostate 2006;66(2):124-34. [PubMed: 16161154]

15. Wang B, Hendricks DT, Wamunyokoli F, Parker MI. A growth-related oncogene/CXC chemokine receptor 2 autocrine loop contributes to cellular proliferation in esophageal cancer. Cancer research 2006;66(6):3071-7. [PubMed: 16540656]

16. Brand S, Dambacher J, Beigel F, et al. CXCR4 and CXCL12 are inversely expressed in colorectal cancer cells and modulate cancer cell migration, invasion and MMP-9 activation. Experimental cell research 2005;310(1):117-30. [PubMed: 16125170]

17. Chinni SR, Sivalogan S, Dong Z, et al. CXCL12/CXCR4 signaling activates Akt-1 and MMP-9 expression in prostate cancer cells: the role of bone microenvironment-associated CXCL12. The Prostate 2006;66(1):32-48. [PubMed: 16114056]

18. Jiang YP, Wu XH, Shi B, Wu WX, Yin GR. Expression of chemokine CXCL12 and its receptor CXCR4 in human epithelial ovarian cancer: an independent prognostic factor for tumor progression. Gynecologic oncology 2006;103(1):226-33. [PubMed: 16631235] 
19. Luker KE, Luker GD. Functions of CXCL12 and CXCR4 in breast cancer. Cancer letters 2006;238 (1):30-41. [PubMed: 16046252]

20. Sasaki K, Natsugoe S, Ishigami S, et al. Expression of CXCL12 and its receptor CXCR4 correlates with lymph node metastasis in submucosal esophageal cancer. J Surg Oncol. 2008

21. Schrader AJ, Lechner O, Templin M, et al. CXCR4/CXCL12 expression and signalling in kidney cancer. British journal of cancer 2002;86(8):1250-6. [PubMed: 11953881]

22. Yasumoto K, Koizumi K, Kawashima A, et al. Role of the CXCL12/CXCR4 axis in peritoneal carcinomatosis of gastric cancer. Cancer research 2006;66(4):2181-7. [PubMed: 16489019]

23. Jiang YP, Wu XH, Xing HY, Du XY. Role of CXCL12 in metastasis of human ovarian cancer. Chinese medical journal 2007;120(14):1251-5. [PubMed: 17697577]

24. Takanami I. Overexpression of CCR7 mRNA in nonsmall cell lung cancer: correlation with lymph node metastasis. International journal of cancer 2003;105(2):186-9.

25. Schimanski CC, Schwald S, Simiantonaki N, et al. Effect of chemokine receptors CXCR4 and CCR7 on the metastatic behavior of human colorectal cancer. Clin Cancer Res 2005;11(5):1743-50. [PubMed: 15755995]

26. Wang J, Xi L, Gooding W, Godfrey TE, Ferris RL. Chemokine receptors 6 and 7 identify a metastatic expression pattern in squamous cell carcinoma of the head and neck. Advances in otorhinolaryngology 2005;62:121-33.

27. Laverdiere C, Hoang BH, Yang R, et al. Messenger RNA expression levels of CXCR4 correlate with metastatic behavior and outcome in patients with osteosarcoma. Clin Cancer Res 2005;11(7):25617. [PubMed: 15814634]

28. Ghobrial IM, Bone ND, Stenson MJ, et al. Expression of the chemokine receptors CXCR4 and CCR7 and disease progression in B-cell chronic lymphocytic leukemia/ small lymphocytic lymphoma. Mayo Clinic proceedings 2004;79(3):318-25. [PubMed: 15008605]

29. Rothenberg ME, Luster AD, Lilly CM, Drazen JM, Leder P. Constitutive and allergen-induced expression of eotaxin mRNA in the guinea pig lung. The Journal of experimental medicine 1995;181 (3):1211-6. [PubMed: 7869037]

30. Luster AD, Rothenberg ME. Role of the monocyte chemoattractant protein and eotaxin subfamily of chemokines in allergic inflammation. Journal of leukocyte biology 1997;62(5):620-33. [PubMed: 9365117]

31. Garcia-Zepeda EA, Rothenberg ME, Ownbey RT, Celestin J, Leder P, Luster AD. Human eotaxin is a specific chemoattractant for eosinophil cells and provides a new mechanism to explain tissue eosinophilia. Nature medicine 1996;2(4):449-56.

32. Garcia-Zepeda EA, Combadiere C, Rothenberg ME, et al. Human monocyte chemoattractant protein (MCP)-4 is a novel CC chemokine with activities on monocytes, eosinophils, and basophils induced in allergic and nonallergic inflammation that signals through the $\mathrm{CC}$ chemokine receptors (CCR)-2 and -3. J Immunol 1996;157(12):5613-26. [PubMed: 8955214]

33. Ponath PD, Qin S, Ringler DJ, et al. Cloning of the human eosinophil chemoattractant, eotaxin. Expression, receptor binding, and functional properties suggest a mechanism for the selective recruitment of eosinophils. The Journal of clinical investigation 1996;97(3):604-12. [PubMed: 8609214]

34. Zhang J, Lathbury LJ, Salamonsen LA. Expression of the chemokine eotaxin and its receptor, CCR3, in human endometrium. Biology of reproduction 2000;62(2):404-11. [PubMed: 10642580]

35. Mochizuki M, Bartels J, Mallet AI, Christophers E, Schroder JM. IL-4 induces eotaxin: a possible mechanism of selective eosinophil recruitment in helminth infection and atopy. J Immunol 1998;160 (1):60-8. [PubMed: 9551956]

36. Ellyard JI, Simson L, Bezos A, Johnston K, Freeman C, Parish CR. Eotaxin selectively binds heparin. An interaction that protects eotaxin from proteolysis and potentiates chemotactic activity in vivo. The Journal of biological chemistry 2007;282(20):15238-47. [PubMed: 17384413]

37. Bertrand CP, Ponath PD. CCR3 blockade as a new therapy for asthma. Expert opinion on investigational drugs 2000;9(1):43-52. [PubMed: 11060659]

38. Combadiere C, Ahuja SK, Murphy PM. Cloning and functional expression of a human eosinophil CC chemokine receptor. The Journal of biological chemistry 1995;270(28):16491-4. [PubMed: 7622448] 
39. Martinelli R, Sabroe I, LaRosa G, Williams TJ, Pease JE. The CC chemokine eotaxin (CCL11) is a partial agonist of CC chemokine receptor $2 b$. The Journal of biological chemistry 2001;276(46): 42957-64. [PubMed: 11559700]

40. Ogilvie P, Bardi G, Clark-Lewis I, Baggiolini M, Uguccioni M. Eotaxin is a natural antagonist for CCR2 and an agonist for CCR5. Blood 2001;97(7):1920-4. [PubMed: 11264152]

41. Zimmermann N, Conkright JJ, Rothenberg ME. CC chemokine receptor-3 undergoes prolonged ligand-induced internalization. The Journal of biological chemistry 1999;274(18):12611-8. [PubMed: 10212240]

42. Daugherty BL, Siciliano SJ, DeMartino JA, Malkowitz L, Sirotina A, Springer MS. Cloning, expression, and characterization of the human eosinophil eotaxin receptor. The Journal of experimental medicine 1996;183(5):2349-54. [PubMed: 8642344]

43. Graziano FM, Cook EB, Stahl JL. Cytokines, chemokines, RANTES, and eotaxin. Allergy Asthma Proc 1999;20(3):141-6. [PubMed: 10389546]

44. Johrer K, Zelle-Rieser C, Perathoner A, et al. Up-regulation of functional chemokine receptor CCR3 in human renal cell carcinoma. Clin Cancer Res 2005;11(7):2459-65. [PubMed: 15814620]

45. Salcedo R, Young HA, Ponce ML, et al. Eotaxin (CCL11) induces in vivo angiogenic responses by human CCR3+ endothelial cells. J Immunol 2001;166(12):7571-8. [PubMed: 11390513]

46. Beck LA, Tancowny B, Brummet ME, et al. Functional analysis of the chemokine receptor CCR3 on airway epithelial cells. J Immunol 2006;177(5):3344-54. [PubMed: 16920975]

47. Kodali R, Hajjou M, Berman AB, et al. Chemokines induce matrix metalloproteinase-2 through activation of epidermal growth factor receptor in arterial smooth muscle cells. Cardiovascular research 2006;69(3):706-15. [PubMed: 16343467]

48. Yurkovetsky ZR, Linkov FY, D EM, Lokshin AE. Multiple biomarker panels for early detection of ovarian cancer. Future Oncol 2006;2(6):733-41. [PubMed: 17155900]

49. Levina V, Marrangoni AM, Demarco R, Gorelik E, Lokshin AE. Multiple effects of TRAIL in human carcinoma cells: Induction of apoptosis, senescence, proliferation, and cytokine production. Experimental cell research 2008;314(7):1605-16. [PubMed: 18313665]

50. Jung T, Schauer U, Heusser C, Neumann C, Rieger C. Detection of intracellular cytokines by flow cytometry. J Immunol Methods 1993;159(12):197-207. [PubMed: 8445253]

51. Siervo-Sassi RR, Marrangoni AM, Feng X, et al. Physiological and molecular effects of Apo2L/ TRAIL and cisplatin in ovarian carcinoma cell lines. Cancer letters 2003;190(1):61-72. [PubMed: 12536078]

52. Rankin SM, Conroy DM, Williams TJ. Eotaxin and eosinophil recruitment: implications for human disease. Molecular medicine today 2000;6(1):20-7. [PubMed: 10637571]

53. Negus RP, Stamp GW, Hadley J, Balkwill FR. Quantitative assessment of the leukocyte infiltrate in ovarian cancer and its relationship to the expression of $\mathrm{C}-\mathrm{C}$ chemokines. The American journal of pathology 1997;150(5):1723-34. [PubMed: 9137096]

54. Miyamasu M, Misaki Y, Yamaguchi M, et al. Regulation of human eotaxin generation by Th1-/Th2derived cytokines. International archives of allergy and immunology 2000;122(Suppl 1):54-8. [PubMed: 10867510]

55. Kampen GT, Stafford S, Adachi T, et al. Eotaxin induces degranulation and chemotaxis of eosinophils through the activation of ERK2 and p38 mitogen-activated protein kinases. Blood 2000;95(6):19117. [PubMed: 10706854]

56. Gubina E, Luo X, Kwon E, Sakamoto K, Shi YF, Mufson RA. betac cytokine receptor-induced stimulation of cAMP response element binding protein phosphorylation requires protein kinase $\mathrm{C}$ in myeloid cells: a novel cytokine signal transduction cascade. J Immunol 2001;167(8):4303-10. [PubMed: 11591753]

57. Impey S, Fong AL, Wang Y, et al. Phosphorylation of CBP mediates transcriptional activation by neural activity and CaM kinase IV. Neuron 2002;34(2):235-44. [PubMed: 11970865]

58. Gardner AM, Vaillancourt RR, Lange-Carter CA, Johnson GL. MEK-1 phosphorylation by MEK kinase, Raf, and mitogen-activated protein kinase: analysis of phosphopeptides and regulation of activity. Molecular biology of the cell 1994;5(2):193-201. [PubMed: 8019005] 
59. Sodhi A, Biswas SK. Monocyte chemoattractant protein-1-induced activation of p42/44 MAPK and c-Jun in murine peritoneal macrophages: a potential pathway for macrophage activation. $\mathrm{J}$ Interferon Cytokine Res 2002;22(5):517-26. [PubMed: 12060490]

60. Rothstein TL, Fischer GM, Tanguay DA, et al. STAT3 activation, chemokine receptor expression, and cyclin-Cdk function in B-1 cells. Current topics in microbiology and immunology 2000;252:12130. [PubMed: 11125469]

61. Taub DD, Ortaldo JR, Turcovski-Corrales SM, Key ML, Longo DL, Murphy WJ. Beta chemokines costimulate lymphocyte cytolysis, proliferation, and lymphokine production. Journal of leukocyte biology 1996;59(1):81-9. [PubMed: 8558072]

62. Ebnet K, Vestweber D. Molecular mechanisms that control leukocyte extravasation: the selectins and the chemokines. Histochemistry and cell biology 1999;112(1):1-23. [PubMed: 10461808]

63. Robinson SC, Scott KA, Balkwill FR. Chemokine stimulation of monocyte matrix metalloproteinase-9 requires endogenous TNF-alpha. European journal of immunology 2002;32(2): 404-12. [PubMed: 11813159]

64. Tessier PA, Naccache PH, Clark-Lewis I, Gladue RP, Neote KS, McColl SR. Chemokine networks in vivo: involvement of $\mathrm{C}-\mathrm{X}-\mathrm{C}$ and $\mathrm{C}-\mathrm{C}$ chemokines in neutrophil extravasation in vivo in response to TNF-alpha. J Immunol 1997;159(7):3595-602. [PubMed: 9317159]

65. Negus RP. The chemokines: cytokines that direct leukocyte migration. Journal of the Royal Society of Medicine 1996;89(6):312-4. [PubMed: 8758187]

66. Youn BS, Kim YJ, Mantel C, Yu KY, Broxmeyer HE. Blocking of c-FLIP(L)--independent cycloheximide-induced apoptosis or Fas-mediated apoptosis by the CC chemokine receptor 9/TECK interaction. Blood 2001;98(4):925-33. [PubMed: 11493434]

67. Kakinuma T, Hwang ST. Chemokines, chemokine receptors, and cancer metastasis. Journal of leukocyte biology 2006;79(4):639-51. [PubMed: 16478915]

68. Milligan G, Smith NJ. Allosteric modulation of heterodimeric G-protein-coupled receptors. Trends in pharmacological sciences 2007;28(12):615-20. [PubMed: 18022255]

69. Zlotnik A, Yoshie O, Nomiyama H. The chemokine and chemokine receptor superfamilies and their molecular evolution. Genome biology 2006;7(12):243. [PubMed: 17201934]

70. Emmelkamp JM, Rockstroh JK. Maraviroc, risks and benefits: a review of the clinical literature. Expert opinion on drug safety 2008;7(5):559-69. [PubMed: 18759708]

71. Wheeler J, McHale M, Jackson V, Penny M. Assessing theoretical risk and benefit suggested by genetic association studies of CCR5: experience in a drug development programme for maraviroc. Antiviral therapy 2007;12(2):233-45. [PubMed: 17503665]

72. Thomas LH, Friedland JS, Sharland M. Chemokines and their receptors in respiratory disease: a therapeutic target for respiratory syncytial virus infection. Expert review of anti-infective therapy 2007;5(3):415-25. [PubMed: 17547506]

73. Sabroe I, Peck MJ, Van Keulen BJ, et al. A small molecule antagonist of chemokine receptors CCR1 and CCR3. Potent inhibition of eosinophil function and CCR3-mediated HIV-1 entry. The Journal of biological chemistry 2000;275(34):25985-92. [PubMed: 10854442]

74. Taub DD, Turcovski-Corrales SM, Key ML, Longo DL, Murphy WJ. Chemokines and T lymphocyte activation: I. Beta chemokines costimulate human T lymphocyte activation in vitro. J Immunol 1996;156(6):2095-103. [PubMed: 8690897]

75. Fioretti F, Fradelizi D, Stoppacciaro A, et al. Reduced tumorigenicity and augmented leukocyte infiltration after monocyte chemotactic protein-3 (MCP-3) gene transfer: perivascular accumulation of dendritic cells in peritumoral tissue and neutrophil recruitment within the tumor. J Immunol 1998;161(1):342-6. [PubMed: 9647242]

76. Manes S, Mira E, Colomer R, et al. CCR5 expression influences the progression of human breast cancer in a p53-dependent manner. The Journal of experimental medicine 2003;198(9):1381-9. [PubMed: 14597737] 

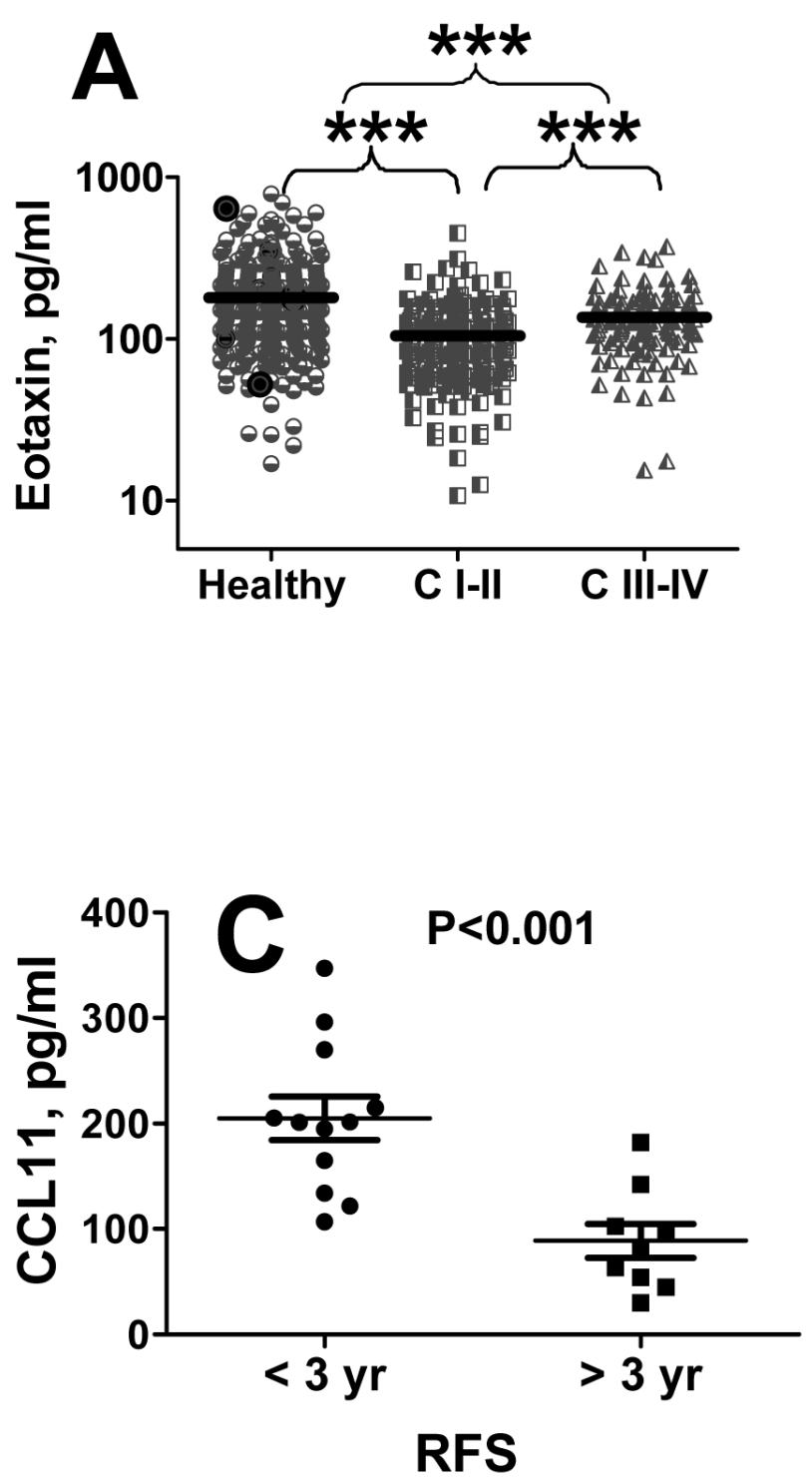
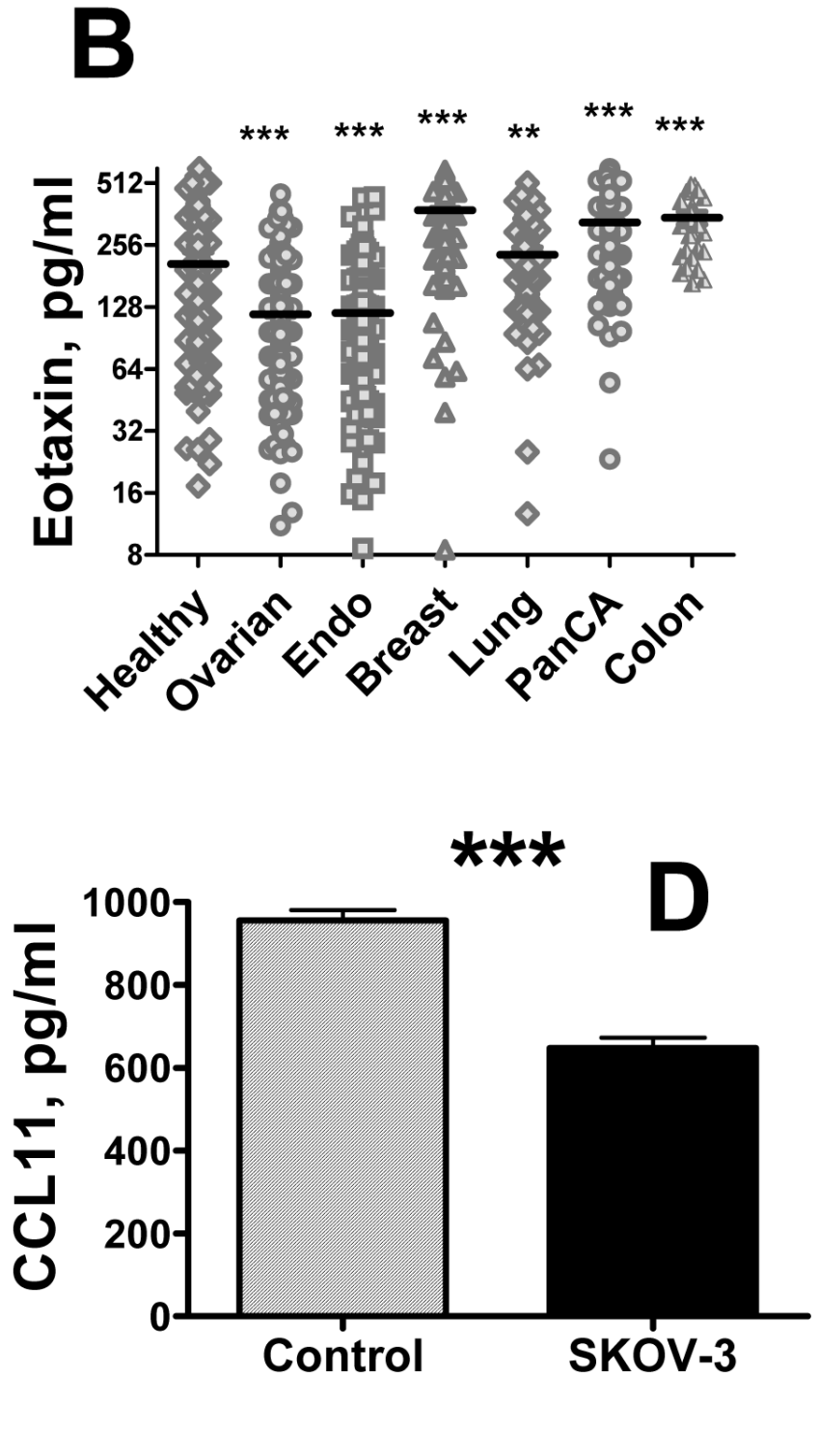

Figure 1. Serum CCL11 in ovarian cancer

Serum CCL11 concentrations were analyzed in healthy controls and patients with early (I-II) and late (III-IV) stages of ovarian cancer (A) and in age-matched women with ovarian (all stages), endometrial, breast, lung, pancreatic, and colon cancers (B) using bead-based immunoassay technology. Reactions were performed according to manufacturer's protocol (Invitrogen). C, Postoperative levels of CCL11 in sera of ovarian cancer patients. CCL11 was measured in postoperatively collected sera using Luminex bead-based assay. Patient group was divided into two subgroups with RFS $<3$ yrs and RFS $>3$ yrs. D, Absorption of CCL11 by cultured ovarian carcinoma cells. Cells $\left(10^{7}\right)$ were trypsinized and resuspended in $3 \mathrm{ml}$ of cell culture medium and CCL11 was added to a final concentration of $1 \mathrm{ng} / \mathrm{ml}$. Cells were incubated with shaking for $1 \mathrm{hr}$, supernatant was collected, and CCL11 concentration was determined by bead-based immunoassay. In this and following Figures, * denotes statistical significance of differences between cancer and healthy at $\mathrm{p}<0.05 ; * *-\mathrm{p}<0.01 ; * * *-\mathrm{p}<0.001$. 


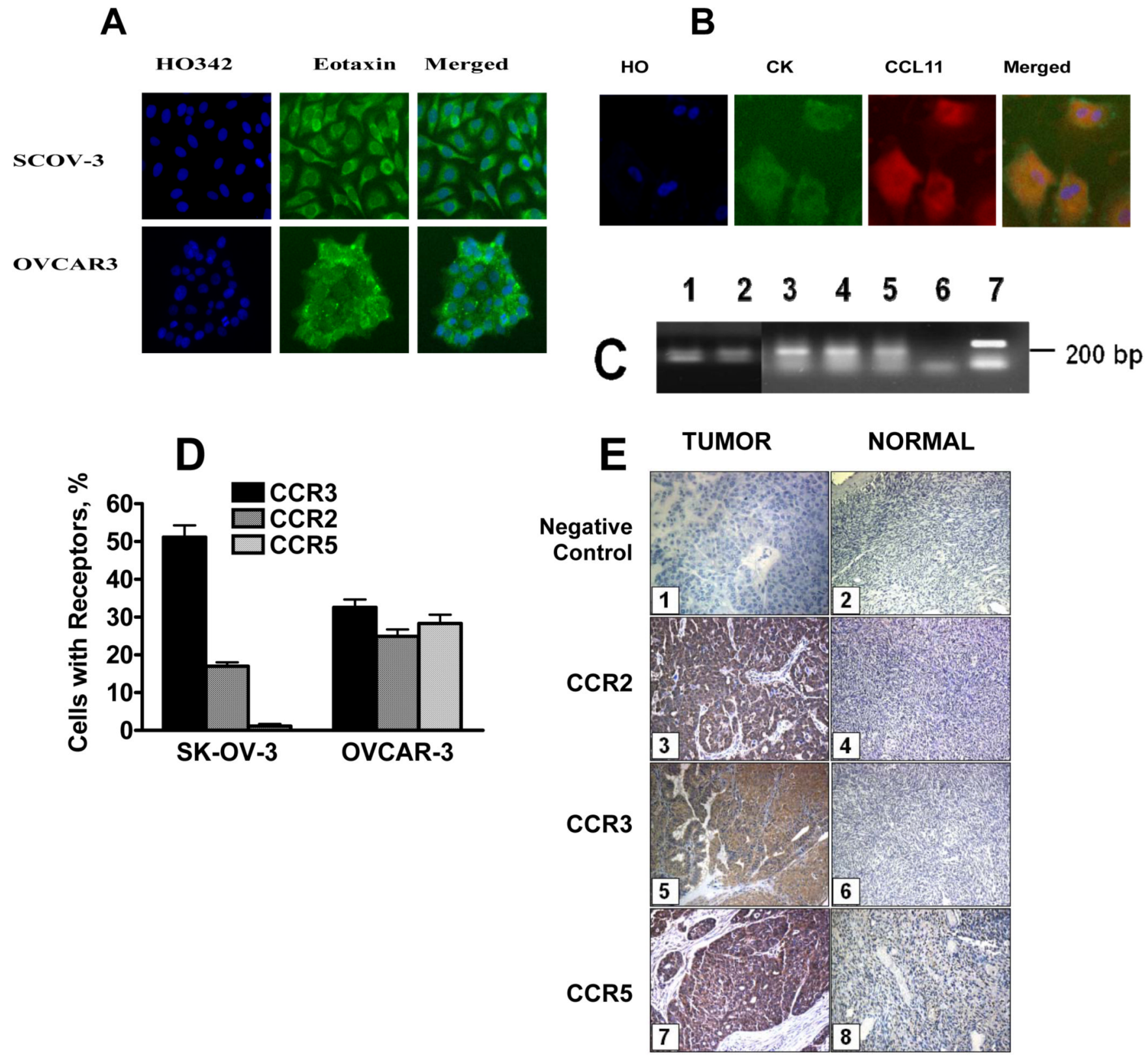

Figure 2. Expression of CCL11 (A-C) and CCR2,3,5 receptors in ovarian carcinoma

A, CCL11 protein expression in ovarian carcinoma cell lines; B, CCL11 protein expression in primary ovarian tumor cells. Primary ovarian carcinoma cells were obtained from ascites fluid. Adherent cells were cultured for 7 days in 96-well plates. These primary and established OVCAR-3 and SKOV-3 cells were pre-incubated with monensin for $48 \mathrm{~h}$, fixed and incubated with primary Abs against CCL11 and secondary Alexa 488 conjugated Abs, counterstained with antibody against cytokeratin 19 (CK) and with Hoechst 33342 and analyzed by Cellomics Array scan (40x objective). C, CCL11 RNA expression in normal ovarian epithelium pooled from 5 healthy women (1), in individual ovarian tumors (2-3), and in cultured ovarian carcinoma cells, OVCAR3 (4) and SKOV3 (5). 6 - negative control; 7 -positive control (Actin). D, CCL11 receptors expression in established cell lines. CCR2,3, and 5 were stained in cultured cells using specific monoclonal FITC-conjugated antibody, and analyzed by flow cytometry. Non-specific antibody binding observed after staining the cells with isotype-matched FITC- 
conjugated IgG control, was subtracted. E, Analysis of CCL11 receptors in ovarian tumors. CCR2,3, and 5 were analyzed in ovarian carcinoma Tissue Array using primary polyclonal Abs optimized to work in FFPR tissues as described in Methods. Tumor sections from 75 different patients and normal ovary sections from 30 healthy women were examined for each receptor with a representative section presented (x200). (1) Negative control on ovarian cancer; (2) Negative control on normal ovary; (3) CCR2 in ovarian cancer (arrow); (4) CCR2 in healthy ovarian epithelium; (5) CCR3 in ovarian cancer (arrow); (6) CCR3 in normal ovary; (7) CCR5 in ovarian cancer; (8) CCR5 in normal ovary. 

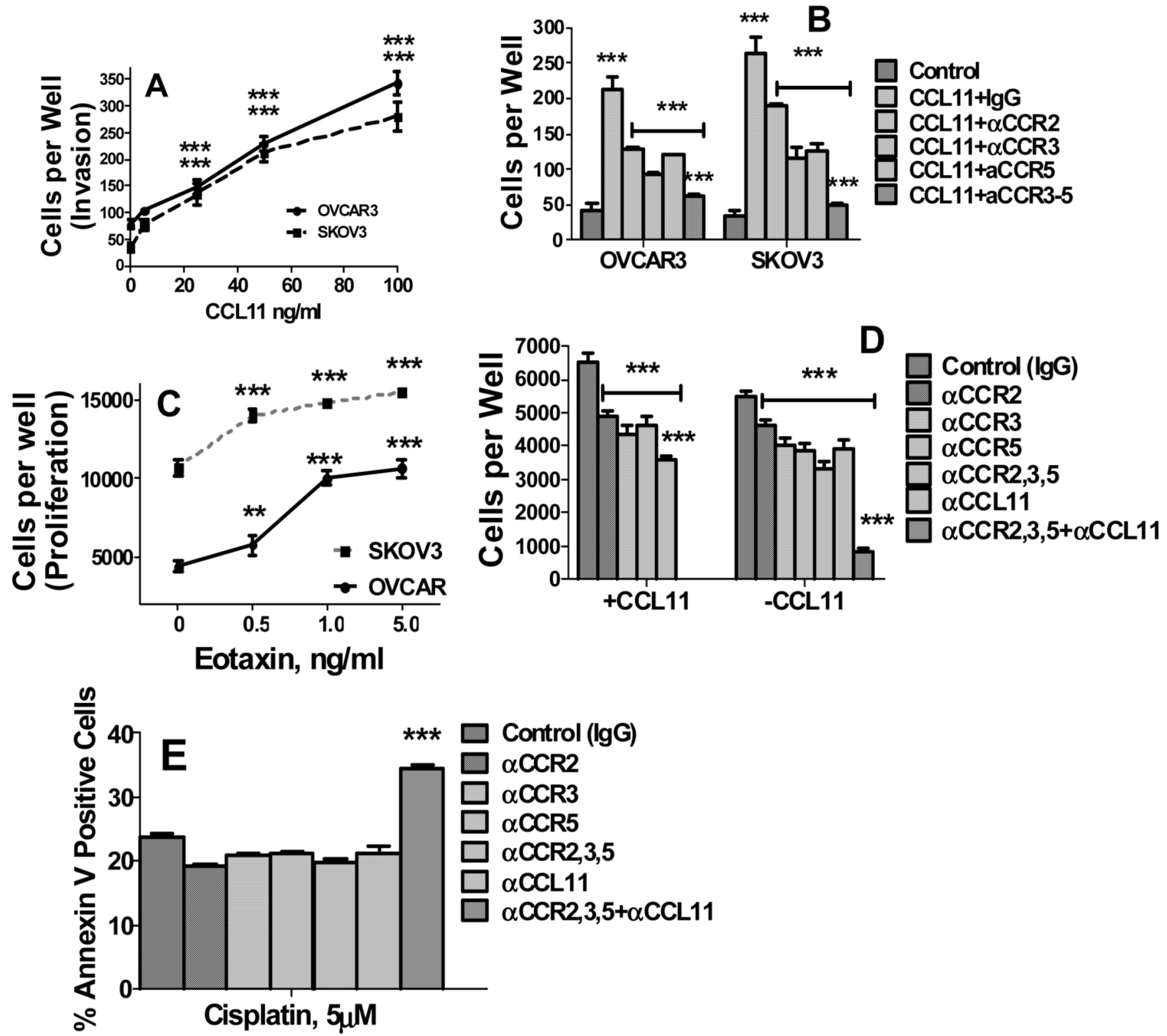

Figure 3. CCL11 induces migration/invasion and proliferation, and neutralizing antibodies against CCL11 and its receptors inhibit proliferation and induce apoptosis in ovarian carcinoma cell lines A, B, Migration/Invasion. Cells were incubated with 0-10 ng/ml CCL11 for $24 \mathrm{hrs}$. Migration/ invasion was measured using BD BioCoat Matrigel Invasion Chambers. A, Dose-curve of CCL11; B, Effects of neutralizing anti-CCR2,3,5 antibodies and their combination on migration/invasion of ovarian carcinoma cells. OVCAR-3 and SKOV-3 cells were pre-treated with $100 \mathrm{ng} / \mathrm{ml}$ neutralizing antibodies against CCR2,3, 5 or IgG isotype control (at $100 \mathrm{ng}$ / $\mathrm{ml}$ ) for $24 \mathrm{~h}$ and cell migration was assessed. C,D, Proliferation. Cell proliferation was evaluated by cell counts using imaging cytometry. C, Dose-curve of CCL11; D, Effects of neutralizing anti-CCL11 and anti-CCR2,3,5 antibodies and their combination on proliferation of untreated and CCL11-treated ovarian carcinoma cells. OVCAR-3 cells were incubated with neutralizing antibodies or IgG isotype control as above for $72 \mathrm{~h}$ and cell proliferation was assessed by imaging cytometry. E, Effects of neutralizing anti-CCL11 and anti-CCR2,3,5 antibodies and their combinations on apoptosis of cisplatin treated ovarian carcinoma cells. 
OVCAR-3 and SKOV-3 cells were incubated with neutralizing antibodies as above for $48 \mathrm{~h}$, cisplatin was added at final concentration of $5 \mu \mathrm{M}$ and incubation continued for additional 24 h. Results for OVCAR-3 cells are presented. Similar results for SKOV-3 cells are not shown. $* * *$ denotes statistical significance of differences at $\mathrm{P}<0.001$. In B and C $* * *$ over CCL11 $+\operatorname{IgG}$ columns indicates statistical significance of differences between CCL11 treated vs. untreated control cells; *** over horizontal lines indicate significance of differences between neutralizing Ab treated cells vs. CCL11 treated cells; *** over anti-CCR2,3,5 combination treated cells indicates significance of differences between cells treated with combination of Abs vs. cells treated with each single neutralizing Ab. 

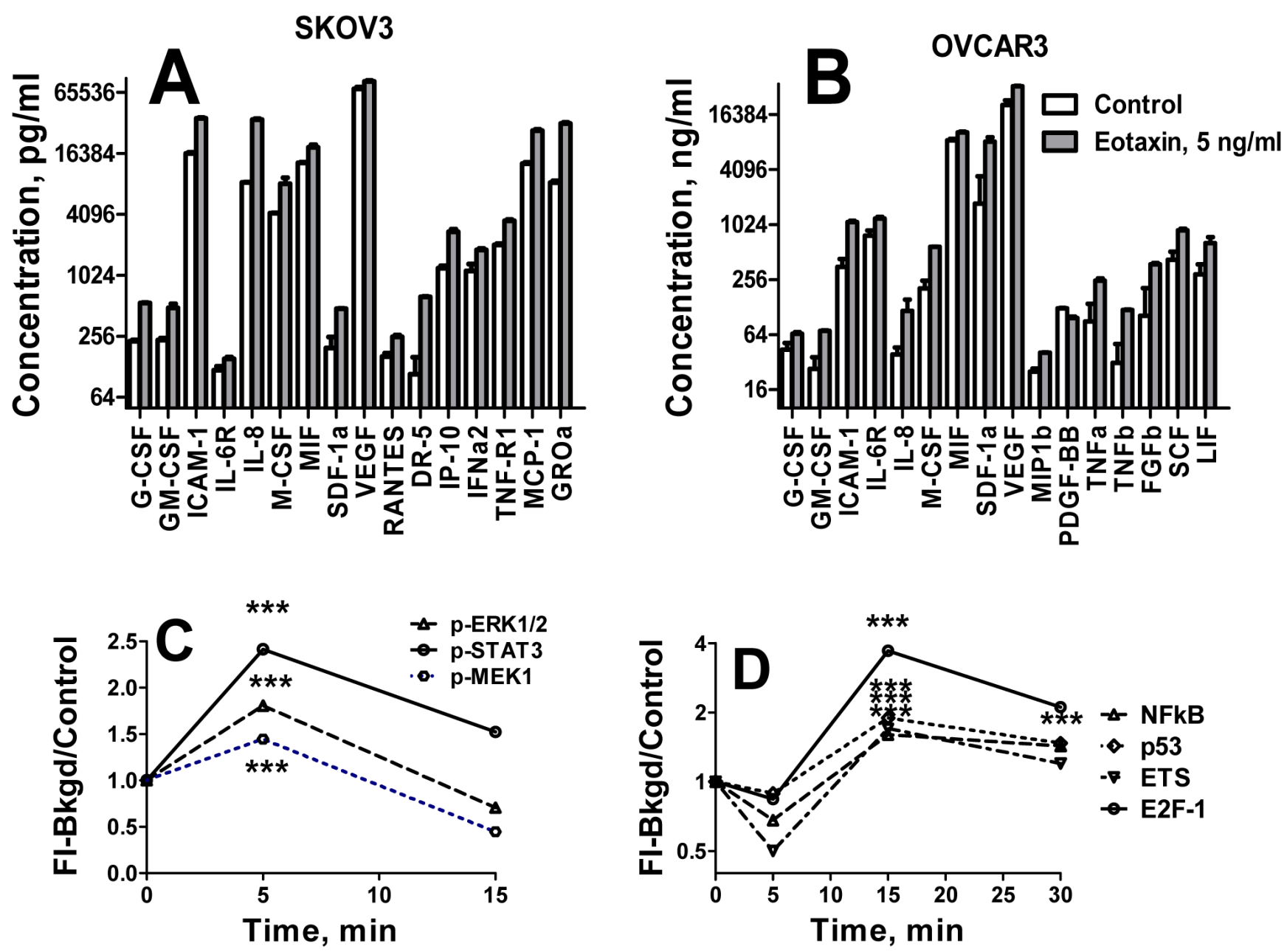

Figure 4. CCL11 induced cytokine production and signal transduction in ovarian carcinoma cell lines

$\mathbf{A , B}$, Induction of cytokines. Media were harvested and cytokine concentrations were measured using XMAP technology with multiplexed cytokine Bio-Rad kit. Data are presented on a logscale. Vertical lines indicate statistical errors, SE. All differences between control and CCL11 treated cells are highly statistically significant $(\mathrm{P}<0.001)$. A, SKOV-3 cells; B, OVCAR-3 cells. C. CCL11 induced phosphorylation of ERK1/2, STAT3, and MEK-1 in OVCAR-3 cells. Tumor cells were treated with $5 \mathrm{ng} / \mathrm{ml}$ of CCL11 for 0-30 min. Cell lysates were prepared and analyzed using 8-Plex phosphoprotein kit as described in Methods. B, Transcription factors expression in CCL11 treated tumor cells. OVCAR-3 and SKOV-3 cells were treated with 5 $\mathrm{ng} / \mathrm{ml}$ of CCL11 for 0,5 , and $30 \mathrm{~min}$. Nuclear extracts were prepared and transcription factor analysis was performed using 40-plex kit. Representative TFs that demonstrated the most robust response to CCL11 treatment are presented. 
Table 1

Expression of CCR 2, 3, 5 in ovarian tissue

\begin{tabular}{|c|c|c|c|c|}
\hline \multirow{2}{*}{ GROUPS } & \multirow{2}{*}{$\mathbf{N}$} & \multicolumn{3}{|c|}{ Receptor Expression, \% Positive } \\
\hline & & CCR2 & CCR3 & CCR5 \\
\hline \multicolumn{5}{|l|}{ Normal vs. Cancer } \\
\hline Normal Ovary & 30 & $17 \%$ & $20 \%$ & $30 \%$ \\
\hline Ovarian Tumor & 75 & $93 \%$ & 67 & 72 \\
\hline \multicolumn{5}{|l|}{ Histology } \\
\hline Serous & 50 & $100 \%$ & $64 \%$ & $74 \%$ \\
\hline Mucinous & 50 & $100 \%$ & $88 \%$ & $100 \%$ \\
\hline Endometrioid & 26 & $77 \%$ & $38 \%$ & $38 \%$ \\
\hline \multicolumn{5}{|l|}{$\underline{\text { Grade }}$} \\
\hline $\mathrm{I}$ & 34 & $92 \%$ & $65 \%$ & $67 \%$ \\
\hline II & 26 & $94 \%$ & $69 \%$ & $69 \%$ \\
\hline III & 54 & $100 \%$ & $74 \%$ & $79 \%$ \\
\hline Correlation between tumor grade and receptors expression (r) & & 0.96 & 1.00 & 0.93 \\
\hline
\end{tabular}

